\title{
Effects of Chocolates Using Low Calorie Cocoa Butter Substitutes on Rat's Plasma Profile and Determination of $S n-1,3$ Position
}

\author{
B. ROS-HANIZA ${ }^{1 *}$ AND S. MAMOT ${ }^{2}$
}

\begin{abstract}
The present study sought to determine the effectiveness of newly developed low calorie chocolate using modified fat through enzymatic interesterification process as cocoa butter substitute of male Sprague Dawley rats $(\mathrm{n}=35)$ compared to cocoa butter as control. Body weight gains did not differ significantly $(\mathrm{p}>0.05)$ in all the test groups fed with chocolates which were using different types of fats. Triacylglycerol and cholesterol test showed no significant difference $(p>0.05)$ for all treatment samples. In this study, a pancreatic lipase hydrolysis was performed to determine the fatty acid composition of the $s n-2$ position of the structure lipids.
\end{abstract}

Key words: Low calorie; chocolates; $s n-1,3$; body weight; plasma profile; fatty acid composition; pancreatic lipase hydrolysis

Cardiovascular disease accounted for approximately $29 \%$ of all deaths worldwide in 2004 and reduction in the consumption of highfat foods is recommended in order to reduce cardiovascular disease burden (WHO 2010). Despite known health risks, it is extremely difficult for people to eat less fat. There have been considerable efforts to reformulate foods to have less energy from fat yet provide comparable sensory qualities by replacing the naturally occurring triacylglycerols with fat substitutes.

Medium-chain TAG (MCT) provides the advantage of being rapidly digested and thus rapidly providing energy. Therefore, they have been used in clinical nutrition for patients suffering from malabsorption. However, these patients also suffer from a lack of essential FA, a problem that is not solved by using MCT.

Human and animal studies conducted during the past $40-50$ years have established that different categories of dietary fatty acids have different effects on blood lipid and lipoprotein levels (Hegsted et al. 1993; Katan et al. 1994). Unsaturated fatty acids found primarily in fats derived from vegetable sources tend to lower total and low density lipoprotein (LDL) cholesterol when compared with saturated fatty acids. On the other hand, saturated fatty acids found primarily in animal fats tend to raise total and LDL-cholesterol when compared with unsaturated fatty acids. For example, linoleic acid, which is abundant in most liquid vegetable oils (e.g. soybean, corn, and safflower), has been associated with blood cholesterol lowering, whereas lauric, myristic, and palmitic acids, common in animal fats and certain vegetable oils (palm and coconut), have been associated with blood cholesterol raising. The saturated fatty acid stearic acid has been reported to have a neutral or lowering effect on total and LDL-cholesterol compared with other saturated fatty acids (Bonanome \& Grundy 1988). The monounsaturated fatty

${ }^{1}$ Felda Global Ventures Research \& Development Sdn. Bhd., Balai Felda, Jalan Gurney 1, 54000 Kuala Lumpur, Malaysia ${ }^{2}$ Universiti Kebangsaan Malaysia, 43600 Bandar Baru Bangi, Selangor, Malaysia

*Corresponding author (e-mail: azminiza@gmail.com) 
acid oleic acid, compared with saturated fatty acids, appears to lower LDL-cholesterol level but to retain high density lipoprotein (HDL) cholesterol (Mattson \& Grundy 1985).

Studies focusing on feeding high levels of specific saturated or unsaturated fatty acids can be difficult to interpret, because fats having similar ratios of unsaturated to saturated fatty acids may have dramatically different fatty acid compositions (Hunter 2001). For example, cocoa butter and milk fat have similar levels of saturation; however, the saturated fatty acids of cocoa butter (expressed as a percentage of total saturated fatty acids) are primarily palmitic (42.5\%) and stearic (55\%) acids, whereas milk fat contains a wider variety of saturated fatty acids including stearic (19\%), palmitic (42\%), myristic (16\%), and medium- (MCFA) and short-chain fatty acids (SCFA) $(\leq 12: 0=23 \%)$. As for palm oil which contain about $51 \%$ saturated fatty acids. As a percentage of total saturated fatty acids, palm oil contains about 9\% stearic and $88 \%$ palmitic acids (Decker 1996).

In addition to overall fatty acid composition, the stereospecific distribution of fatty acids in a particular fat also should be considered when fatty acid effects are examined. Fatty acids can occupy any of three positions on the glycerol backbone, designated as $s n-1, s n-2$, and $s n-3$ ( " $s n$ " stands for "stereospecific numbering"). Oils and fats of plant origin, such as soybean oil and cocoa butter, contain unsaturated fatty acids in the $s n-2$ position and saturated fatty acids in the $s n-1$ and $s n-3$ positions. The stereospecific position of fatty acids on triglycerides plays a major role in the functionality of fats in food products. Cocoa butter, the unique positioning of palmitic, oleic, and stearic acids in two predominant triglyceride forms gives cocoa butter a sharp melting point just below body temperature. The way cocoa butter melts is one of the reasons for the pleasant eating quality of chocolate. The unique functionalities attributed to the location of specific fatty acids in fats, such as cocoa butter, is difficult to duplicate in fat substitutes (Hunter 2001).

The stereospecific position of fatty acids is important because it determines how triglycerides are digested. These investigators showed that during digestion in the gastrointestinal tract, pancreatic lipase, an enzyme highly specific for the $s n-1$ and $s n-3$ esters, catalyzes the formation of $s n-2$ monoglycerides and free fatty acids that are absorbed in the small intestine. The 2-monoglycerides are reacylated into new triglycerides that enter the lymph chylomicrons. Fatty acids released from the $s n-1$ and $s n-3$ positions often have different metabolic fates than fatty acids retained in the $s n-2$ position. These metabolic fates depend on the fatty acid chainlength and stereospecific location on the triglyceride. SCFA and MCFA $(\leq 10$ carbon atoms) can be solubilized in the aqueous phase of the intestinal contents, where they are absorbed, bound to albumin, and transported to the liver by the portal vein. Longer-chain fatty acids, such as palmitic and stearic, have low coefficients of absorption because of melting points above body temperature and because of their ability to form calcium soaps.

The role of stereospecific location of dietary fatty acids can be studied using a process called interesterification (sometimes referred to as randomization), in which the positions of the fatty acids on the glycerol backbone are rearranged. Interesterification is accomplished by catalytic methods at relatively low temperature and permits the exchange of fatty acids both within and between triacylglycerols. The process may be enzymatic (i.e. highly controlled) or chemical (i.e. relatively uncontrolled). The food industry uses interesterification (largely chemical) to modify the melting and crystallization behaviour of fats. Also, the hardening of a liquid oil by interesterifying it with a solid fat offers an alternative to the use of partial hydrogenation in the manufacture of margarines and spreads. This exchange of fatty acids results in their 
randomization among all three stereospecific positions. Thus, a naturally occurring fat having oleic acid primarily in the $s n-2$ position after interesterification could have oleic acid roughly equally distributed among the $s n-1$, $s n-2$, and $s n-3$ positions (Hunter 2001). The positional distribution of MCFA in the dietary fat had no significant effect on lymph flow, triglyceride output, or lipid composition of the chylomicrons. The positional distribution of $s n-2$ fatty acids in the synthetic triglycerides was largely maintained in the chylomicron triglycerides. These results indicated that fatty acids with chain lengths less than 10 in the dietary triglycerides are transported by the lymphatic system, and the positional distribution is preserved in chylomicron triglycerides. The interesterification (randomization) process does not change the degree of unsaturation or the isomeric state of the fatty acids, as they transfer in their entirety from one position to another. Interesterification thus allows investigators to compare nutritional effects of diets that are identical in fatty acid composition but different in triacylglycerol composition. Randomization of naturally occurring fats could have implications regarding cardiovascular health. Early events in the metabolic processing of dietary triglycerides may have an important impact on the risk of chronic diseases such as coronary heart disease. By using structured triglycerides containing predominantly stearic and oleic acids, Summers et al. assessed the possibility that the initial removal of fatty acids from chylomicron triglycerides might be fatty acid-specific. The hypothesis was that a stearoyl chain at the $s n-2$ position of chylomicron triglyceride might hinder lipoprotein lipase action and thus clearance of stearic acid.

Our aim in this study was to determine the position of fatty acids at $s n-1$ and $s n-3$ in of low calorie CBS and the effects to the experimental animals (rats). The nutritional value of the chocolate to the rats was also observed through their body weight gain and plasma cholesterol level.

\section{MATERIALS AND METHODS}

\section{Source of Chocolates}

Newly developed chocolates using five types of fats $(\mathrm{CBS} 1=\mathrm{PMF}, \mathrm{CBS} 5=\mathrm{PKS}, \mathrm{CBS} 2=$ PMF:PKS, SCBS2 = EIE PMF:PKS:MCT, CB) were prepared using cocoa powder, fats, skim milk powder, emulsifier, vanillin and sucrose. Cocoa powder purchased from Pastry Pro Sdn. Bhd. at Kepong, Malaysia, skimmed milk from Promac Enterprises Sdn. Bhd., cocoa butter (CB) from Malaysian Cocoa Board, Bangi, Malaysia.

\section{Rats and Experimental Design}

Male Sprague Dawley rats $(\mathrm{n}=35,2$ months of age, $200 \mathrm{~g}-250 \mathrm{~g}$ of weight) were obtained from Animal House, Universiti Kebangsaan Malaysia, Bangi. All treatments and diets were reviewed and approved by the Animal House of University Kebangsaan Malaysia, Bangi, Selangor. After arrival, rats were quarantined for a week (wk) during which they were fed with rodent chow (control) diet (Barastoc Rat \& Mouse Cubes, Ridley Agri Products).

Rats were then divided randomly into five experimental groups $(n=7)$ and were housed individually under controlled temperature $\left(25^{\circ} \mathrm{C}\right)$ with a $12 \mathrm{~h}$ light:dark cycle and fed about $15 \mathrm{~g}$ control diet followed by experimental diets for four weeks (oral feed). Rats had free access to water and were weighed weekly throughout the study. Treatments given to experimental rats were as follows.

\section{Sampling and Analytical Procedures}

The body weight of each rat was recorded weekly. On the final day of the experimental period, wk-1(7d), -2(14d), -3(21d) and 4-(28d), rats were fasted overnight and killed by chloroform inhalation.

Blood samples of fasting rats were collected immediately in sterile tubes with EDTA-K3 by heart vena puncture (before rats were killed). 
Table 1. Diet treatment for Wistar rats

\begin{tabular}{c|cc}
\hline Group & n of rats & Control diet + experimental diet \\
\hline A & 7 & $15 \mathrm{~g}$ control diet $+5 \mathrm{~g} \mathrm{CBS} 1$ \\
$\mathrm{~B}$ & 7 & $15 \mathrm{~g}$ control diet $+5 \mathrm{~g} \mathrm{CBS} 5$ \\
$\mathrm{C}$ & 7 & $15 \mathrm{~g}$ control diet $+5 \mathrm{~g} \mathrm{CBS} 2$ \\
$\mathrm{D}$ & 7 & $15 \mathrm{~g}$ control diet $+5 \mathrm{~g} \mathrm{SCBS} 2$ \\
$\mathrm{E}$ & 7 & $15 \mathrm{~g}$ control diet $+5 \mathrm{~g} \mathrm{CB}$ \\
\hline
\end{tabular}

$5 \% \mathrm{w} / \mathrm{w}$ doses in rats were equivalent to approximately $5 \mathrm{~g} /$ day in human diet by Rao (2001) \& Bouhnik et al. (1999).

Tube with blood samples were kept in ice box immediately to avoid from heamolysis occurred. Samples were centrifuged for $15 \mathrm{~min}$ at $3000 \times \mathrm{g}$, at $4^{\circ} \mathrm{C}$ using Centrifuge Micro $22 \mathrm{R}$ (Hettich, Germany) to get the blood plasma. The plasma samples were transferred to tube adapter and kept it in low ultra freezer at $-70^{\circ} \mathrm{C}$. The plasma samples were defrosted at $\pm 20^{\circ} \mathrm{C}$ for biochemistry analysis. The plasma samples were measured for total cholesterol, triacylglycerols, HDL and LDL using Blood Analyzer Clinic Chem-Vitalab Selectra E Analyzer.

\section{Determination of Fatty Acid Composition at the $S n-1,2$ and 3 of Triacylglycerols of Fats (AOCS Ch 3-91)}

(a) Neutralization and purification especially for enzymatic interesterification fat before lipase hydrolysis.

(b) Lipase hydrolysis: $0.1 \mathrm{ml}$ oil was pipette into a flask. $0.2 \mathrm{ml}$ calcium chloride and $0.5 \mathrm{ml}$ bile salt solution were added and capped. Mixture was incubated while shaking at $40^{\circ} \mathrm{C}$ for $5 \mathrm{~min} .2 \mathrm{ml}$ lipase solution was added. The reaction was stopped and $1 \mathrm{ml}$ HCL was added. $3 \mathrm{ml} \times 2 \mathrm{ml}$ chloroform was added. All rinsed chloroform was transferred into a separating funnel. Mixture was kept for several hours before filtered and evaporated. The neat lipid mixture was ready for thin layer chromatography (TLC).

(c) TLC: Merck multipurpose $20 \times 20$ plate (TLC silica gel 60) was dried at $100^{\circ} \mathrm{C}$ for several hours. $100 \mu \mathrm{l}$ chloroform was added to the neat lipid extract obtained above with syringe and blunt-tip needle. It was transferred onto the plate as a straight line about $2 \mathrm{~cm}$ to $2.5 \mathrm{~cm}$ above the lower edge of the plate. The plate was developed in hexane:diethyl ether:formic acid 70:30:1 $\mathrm{v} / \mathrm{v} / \mathrm{v}$ for $1.5 \mathrm{~h}$ to $2 \mathrm{~h}$. The plate was dyed with dicholofluorescein spray and the bands were visualized under UV light. The MAG band was isolated by scraping the silica coating off the plate.

(d) Analysis of FAME

(e) Calculation of results.

A modified version of Luddy et al. (Decker 1996) was used to perform pancreatic lipase hydrolysis to determine the fatty acids at the $s n-2$ position of the structured lipids (SL) products.

\section{Statistical Analyses}

All data obtained were analyzed using SPSS Inc. software (version 10.0.1). One-way ANOVA was used to determine a significant difference between means of the dietary groups and sampling sites with a significance level of $\mathrm{p}<0.05$. 


\section{RESULTS AND DISCUSSION}

\section{Rat's Body Weight}

During the 4 week experiment, body weight (BW) gains did not differ significantly $(\mathrm{p}>0.05)$ among the rats fed with control and the different experimental diets as shown in Figure 1.

However, rats fed with $A$ and $C$ showed highest BW gain (31\%) compared to $B, D$ and $E$ group. All rats were generally healthy throughout the feeding trial period. While group $D$ [low calorie cocoa butter substitute (CBS)] showed the lowest weight gain with only $26 \%$.

\section{Plasma Profile}

The plasma profile of treated and control rats, which comprised of cholesterol, triacylglycerols, HDL and LDL contents at the beginning and the end of each treatment period is shown in Table 2. No significant difference $(p>0.05)$ in plasma cholesterols, triacylglycerols, HDL and LDL contents of rats fed with control diet and other experimental diets were evident. However, rats fed with $D(2.07 \mathrm{mmol} / \mathrm{l})$ and $E(1.86 \mathrm{mmol} / \mathrm{l})$ showed much lower concentrations in cholesterol when compared with the $A(2.36 \mathrm{mmol} / \mathrm{l}), B(2.25$ $\mathrm{mmol} / \mathrm{l})$ and $C(2.27 \mathrm{mmol} / \mathrm{l})$ after the final day

Body weight $(\mathrm{g})$
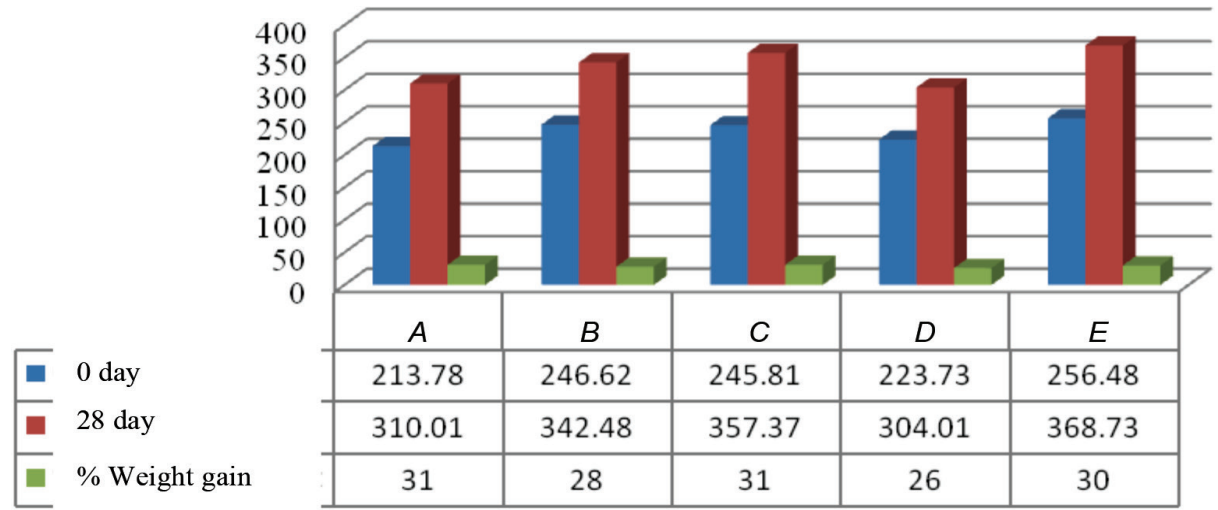

*Percentage of body weight gain for $\mathrm{A}^{\mathrm{a}}, \mathrm{B}^{\mathrm{a}}, \mathrm{C}^{\mathrm{a}}, \mathrm{D}^{\mathrm{a}}, \mathrm{E}^{\mathrm{a}}(\mathrm{p}>0.05)$, showed no significant differences.

Figure 1. Body weight gain before and after treatments of rats fed with control and experimental diets.

Table 2. Effects of lipid absorption of rats after treatment with control diet and experimental sample.

\begin{tabular}{c|cccc}
\hline Group & $\begin{array}{c}\text { Cholesterol } \\
(\mathrm{mmol} / \mathrm{l})\end{array}$ & $\begin{array}{c}\text { TAG } \\
(\mathrm{mmol} / \mathrm{l})\end{array}$ & $\begin{array}{c}\text { LDL-cholesterol } \\
(\mathrm{mmol} / \mathrm{l})\end{array}$ & $\begin{array}{c}\text { HDL-cholesterol } \\
(\mathrm{mmol} / \mathrm{l})\end{array}$ \\
\hline$A$ & $2.36^{\mathrm{a}}$ & $0.65^{\mathrm{a}}$ & $1.531^{\mathrm{a}}$ & $0.54^{\mathrm{a}}$ \\
$B$ & $2.25^{\mathrm{a}}$ & $0.805^{\mathrm{a}}$ & $1.407^{\mathrm{a}}$ & $0.47^{\mathrm{a}}$ \\
$C$ & $2.27^{\mathrm{a}}$ & $0.985^{\mathrm{a}}$ & $1.314^{\mathrm{a}}$ & $0.51^{\mathrm{a}}$ \\
$D$ & $2.07^{\mathrm{a}}$ & $1.51^{\mathrm{a}}$ & $0.859^{\mathrm{a}}$ & $0.53^{\mathrm{a}}$ \\
$E$ & $1.86^{\mathrm{a}}$ & $1.02^{\mathrm{a}}$ & $0.878^{\mathrm{a}}$ & $0.52^{\mathrm{a}}$ \\
\hline
\end{tabular}

${ }^{a}$ Means in the same column followed by same lowercase alphabet is not significantly different at $\mathrm{p}>0.05$. 
of treatment. Same things occurred for LDLcholesterols of $D$ and $E$ group showed lower concentrations, $859 \mathrm{mmol} / \mathrm{l}$ and $878 \mathrm{mmol} / \mathrm{l}$, respectively. These results as an indicator to explained the effective reaction of blood cholesterol in human body. These findings suggest that the MCFA was metabolized quickly for energy, and that different fatty acids (FAs) in the diet may eventually lead to change in fatty acid composition of the liver (Osborn \& Akoh 2002). SCBS2 containing MCFAs and PUFAs could be a therapeutic or medical lipid source, and may be useful in enteral and parenteral nutrition. This SCBS2 could decrease serum cholesterols and TAGs. It may also reduce the rate of body weight gain, because the MCFAs were metabolized more rapidly in the body.

\section{Pancreatic Lipase Study}

R. miehei preferentially hydrolyzes the fatty acids at the $s n-1$ and 3 positions of TAG. This characteristic is especially desirable when the nutritional benefits of TAG are considered, largely because specialty oils with desired fatty acids at specific positions can be prepared with $s n$-1,3-specific lipases. Several studies have shown that the nature of the fatty acids and their positions in a glycerol molecule can affect their metabolism, availability as an energy source, and as an essential fatty acid source. Jandacek et al. reported that a TAG with octanoic acid at the $s n-1$ and 3 positions and long-chain fatty acids (LCFA) at the $s n-2$ position were hydrolyzed and absorbed more efficiently than TAG composed of only LCFA. Christensen et al. reported that a defined TAG molecule with MCFA at the $s n-1,3$ positions could be a better source of fat. They observed increased absorption of essential fatty acids at the $s n-2$ position of glycerol. In this study, a pancreatic lipase hydrolysis was performed to determine the fatty acid composition of the $s n-2$ position of the SL. Pancreatic lipase hydrolysis was performed to determine the fatty acid composition at the $s n-2$ position (Table 3). Values for SCBS showed that lipase incorporated $17.8 \%$ of MCFA and $75.7 \%$ of LCFA at the $s n-2$ position. While at $s n-1,3$ position showed slightly high content of MCFA (23\%) and only $72.7 \%$ of LCFA. Lipase RM IM was able to produce SL that contained specific fatty acids at the $s n-1,3$ positions. The SCBS2 prepared in this study are potentially useful as reduced-calorie oils similar to Salatrim ${ }^{\circledR}$. It contains desirable functional fatty acids in the same molecule and may provide rapid delivery of energy.

Table 3. Fatty acids content at position sn-1, 2 and 3.

\begin{tabular}{l|cccccccccc}
\hline \multicolumn{1}{c}{ Sample } & $8: 0$ & $10: 0$ & $12: 0$ & $14: 0$ & $16: 0$ & $16: 1$ & $18: 0$ & $18: 1$ & $18: 2$ & $20: 0$ \\
\hline CBS5 & & & & & & & & & & \\
$s n-2$ & & & 52.1 & 25.5 & 9.9 & & 1.4 & 9.5 & 1.5 & \\
$s n-1 \& 3$ & 2 & 2.8 & 55 & 21.9 & 8.7 & & 2 & 6.6 & 1 & \\
CBS1 & & & & & & & & & & \\
$s n-2$ & & & & 0.7 & 14.7 & 0.6 & 1.6 & 75.3 & 7 & \\
$s n-1 \& 3$ & & & & 0.8 & 57 & & 6 & 32.1 & 3.3 & 0.4 \\
CBS2 & & & & & & & & & & \\
$s n-2$ & 3.5 & 3.7 & 14.4 & 6.9 & 12.5 & & 1.4 & 52.5 & 5.5 & \\
$s n-1 \& 3$ & 4.5 & 3.9 & 11.2 & 4.6 & 56.6 & & 6.7 & 12.2 & 1.2 & \\
SCBS2 & & & & & & & & & & \\
$s n-2$ & 0.7 & 3.1 & 14 & 6.5 & 12.1 & & 1.2 & 56.5 & 5.9 & \\
$s n-1 \& 3$ & 7.3 & 4.5 & 11.2 & 4.9 & 57.0 & & 6.5 & 8.4 & 0.8 & \\
\hline
\end{tabular}




\section{ACKNOWLEDGEMENT}

The authors wish to thank Malaysian Palm Oil Board, Malaysia for sponsorship $(\mathrm{PhD})$ of the study. Acknowledgment is also extended to the supervisor from Universiti Kebangsaan Malaysia.

Date of submission: January 2014

Date of acceptance: April 2014

\section{REFERENCES}

Bonanome, A. \& Grundy, SM 1988, 'Effect of dietary stearic acid on plasma cholesterol and lipoprotein levels, N. Engl. J. Med., vol. 318, pp. 1244-1248.

Christensen, MS, Mullertz, A \& Hoy C 1995, 'Absorption of triglycerides with defined or random structure by rats with biliary and pancreatic diversion', Lipids, vol. 30, no. 6, pp. 521-526.

Decker, EA 1996, 'The role of stereospecific saturated fatty acid positions on lipid metabolism', Nutr. Rev., vol. 54, pp. 108-110.

Hegsted, DM, Ausman, LM, Johnson, JA \& Dallal, GE 1993, 'Dietary fat and serum lipids: an evaluation of the experimental data', Am. J. Clin. Nutr., vol. 57, pp. 875-883.

Hunter, JE 2001, 'Studies on effects of dietary fatty acids as related to their position on triglycerides', J. Lipid, vol. 36, pp. 655-668.
Jandacek, RJ, Whiteside, JA, Holcombe, BN, Volpenhein, RA \& Taulbee, JD 1987, 'The rapid hydrolysis and efficient absorption of triglycerides with octanoic acid in the 1and 3-positions and long-chain fatty acid in the 2-position', Am. J. Clin. Nutr., vol. 45, pp. 940-945.

Katan, MB., Zock, PL \& Mensink, RP 1994 'Effects of Fats and fatty acids on blood lipids in humans: an overview', Am. J. Clin. Nutr., vol. 60 (suppl.), pp. 1017S-1022S.

Mattson, FH \& Grundy, SM 1985, 'Comparison of effects of dietary saturated, monounsaturated, and polyunsaturated fatty acids on plasma lipids and lipoproteins in man', J. Lipid Res., vol. 26, pp. 194-202.

$\mathrm{Mu}, \mathrm{H}$ \& Hoy, C-E 2002, 'Distribution of medium-chain FA in different lipid classes after administration of specific structured TAG in rats,' Lipids, vol. 37, pp. 329-331.

Osborn HT \& Akoh CC 2002, 'Structured lipidsnovel fats with medical, nutraceutical, and food applications', in Comprehensive reviews in food science \& food safety, vol. 3 .

Summers, LKM, Fielding, BA, Herd, SL, Ilie, V, Clark, ML, Quinlan, PT \& Frayn, KN 1999, 'Use of structured triacylglycerols containing predominantly stearic and oleic acids to probe early events in metabolic processing of dietary fat', J. Lipid Res., vol. 40, pp. 1890-1898.

World Health Organization 2009, 'Fact sheet \# 317, cardiovascular diseases updated Sept 2009, viewed May 2010, <http://www.who.int/ mediacentre/factsheets/fs317/en/index.html >. 